\title{
Intensity-modulated Radiotherapy Planning at Mediastinal Lymphoma Treatment: Sandglass, Rainbow and Butterfly Techniques
}

\author{
(1) Serap YÜCEL, (1) Zeynep GÜRAL, (1) Fulya AĞAOĞLU \\ 'Department of Radiation Oncology, Acıbadem Atakent Hospital, Istanbul-Turkey
}

\begin{abstract}
OBJECTIVE
We developed "sandglass" technique using volumetric arc therapy (VMAT) with two avoidance sectors and make comparison between two intensity-modulated radiotherapy (IMRT) techniques, "butterfly" with three anterior and two posterior beams, and "rainbow" with five anterior beams. Conformity index (CI), homogeneity index (HI), organ of risk doses, and monitor unit (MU) values are used as evaluation tools.

\section{METHODS}

IMRT and VMAT plans generated for 15 mediastinal lymphoma patients. Sandglass technique consists of two full arc with avoidance sectors $\left(240^{\circ}-300^{\circ}\right.$ and $\left.60^{\circ}-120^{\circ}\right)$, butterfly technique with five static fields $\left(0^{\circ}, 40^{\circ}, 160^{\circ}, 190^{\circ}\right.$, and $\left.330^{\circ}\right)$, and rainbow technique has five static fields $\left(0^{\circ}, 20^{\circ}, 40^{\circ}, 320^{\circ}\right.$, and $\left.345^{\circ}\right)$. The prescribed treatment dose was $30.6 \mathrm{~Gy}$ in 17 fractions. Dosimetric data were compared using crosspaired sample t-test.
\end{abstract}

\section{RESULTS}

Lung V5 doses were 41.62-50.74\%, V20 doses were 12.72-16.21\%, heart mean doses were between 454 and $509 \mathrm{cGy}$, spinal cord max point doses were between 2210 and $2798 \mathrm{cGy}$, esophagus mean doses were between 1309 and $1409 \mathrm{cGyHI}, \mathrm{CI}$, and MU values were calculated. Lung V20, mean esophagus, and mean heart and spinal cord max. point doses were observed significantly lower at sandglass technique $(\mathrm{p}=0.001$, $\mathrm{p}=0.02, \mathrm{p}=0.013$, and $\mathrm{p}=0.001$ ). $\mathrm{CI}$ is significantly better than other two techniques (rainbow $\mathrm{p}=0.000$ and butterfly $\mathrm{p}=0.001)$. On the other hand, lung V5 doses significantly lower at rainbow technique $(\mathrm{p}=0.035)$, besides, HI has significant advantage with respect to others. Sandglass has lower MU value with $484 \mathrm{MU}$.

\section{CONCLUSION}

Sandglass technique has remarkable advantageous for lung V20, heart, esophagus, spinal cord, CI, and MU. Treatment plans with lower critical organ doses have great importance in terms of late side effects in patients with long survival expectancy. Sandglass plan was preferable for mediastinal lymphoma.

Keywords: Intensity-modulated radiotherapy; lymphoma; mediastinum; volumetric arc therapy. Copyright $\odot$ 2022, Turkish Society for Radiation Oncology

\section{Introduction}

The progress in radiotherapy (RT) and chemotherapy (CT) has dramatically changed the treatment modalities in lymphomas.[1] Lymphomas, including Hodgkin's and non-Hodgkin's, have high cure rates with advances in CT and RT, therefore, long-term adverse effects are getting more important.[2-4] Increased risk of secondary cancers and cardiovascular disease at these patients has been showed in long-term follow-up studies 
at the past publications.[5-10] Recently, more advances in RT techniques and newly CT regimes give the patient the opportunity on behalf of long-term late effects.

Standard three-dimensional conformal RT (3DCRT) techniques include anterior-posterior/posterior-anterior field which are with variation of energies for optimal dose distribution. According to dosimetric studies, advanced RT techniques such as intensity-modulated radiotherapy (IMRT) have better tumor coverage and reduced toxicity to organs at risk (OARs) with respect to 3D-CRT.[11] Choosing an optimal RT technique for mediastinal lymphoma patients is controversial. Xu et al.[12] compared volumetric arc therapy (VMAT) with seven and nine fields IMRT plans and concluded that VMAT achieved similar dose distributions and is not always superior to VMAT. Weber et al.[13] reported that VMAT has clear advantages for PTV and OAR to IMRT.

We herein report an assessment of comparative planning studies of VMAT and IMRT techniques. IMRT plans have five fields with butterfly and rainbows arrangement. VMAT consists of two full arcs with total $120^{\circ}$ avoidance sectors to reduce low-dose bath to lungs.

\section{Materials and Methods}

We retrospectively analyzed 15 mediastinal lymphoma patients treated with IMRT between 2015 and 2018. Patients were simulated supine on a wing board. Eclipse TPS station Version 13.6 (Varian, Palo Alto, USA) was used for contouring and dosimetric planning. Involved-site RT principals were followed to create clinical target volüme (CTV) and a uniform $5 \mathrm{~mm}$ expansion was applied to the CTV to create the PTV.

VMAT and IMRT plans were optimized on Eclipse TPS station Version 13.6 (Varian, Palo Alto, USA) and using same optimization objectives for them. Six MV beam energy was used for all plans and dose distribu- tions calculated using anisotropic analytical algorithm with $2.5 \mathrm{~mm}$ grid size. Three different RT plans were generated for each patient.

Butterfly and butterfly technique had five gantry static fields with $\left(0^{\circ}, 40^{\circ}, 160^{\circ}, 190^{\circ}\right.$, and $\left.330^{\circ}\right)$ and $\left(0^{\circ}, 20^{\circ}, 40^{\circ}, 320^{\circ}\right.$, and $\left.345^{\circ}\right)$ angle distributions. Sunglass technique has two arcs with counterclockwise from $179^{\circ}$ to $181^{\circ}$ and clockwise $181^{\circ}-179^{\circ}$ and optimized with avoiding sectors between $240^{\circ}-300^{\circ}$ and $60^{\circ}-120^{\circ}$ (Fig. 1).

\section{Plan Evaluation}

Dose coverage, monitor unit (MU), and OAR doses were compared between plans. Dose-volume histograms were used for quantitative evaluations. Dosimetric parameters of OARs were as follows; lungs V5, lungs V20, spinal cord Dmax, mean esophagus, and heart doses. Analyzed parameters for PTV were; volume of PTVs, the treated volume of the prescribed isodose line (PTV95), the portion of the PTV within the prescribed isodose line $\left(\mathrm{PTV}_{\mathrm{PIV}}\right)$, the minimum doses delivered to $5 \%$ of the PTV (D5\%), and the minimum doses delivered to $95 \%$ of the PTV (D95\%).

The conformity index is defined as a ratio between the volume covered by the reference isodose according to ICRU is $95 \%$ isodose and the target volume and optimal conformity index $(\mathrm{CI})=1$, calculated using formula $\mathrm{CI}=\left(\mathrm{PTV}_{\mathrm{PIV}}\right)^{2} /\left(\mathrm{PTV}^{\star} \mathrm{PIV}\right)$ as described by Paddick. [8] The homogeneity index (HI) described as a ratio between the maximum dose in the target volume and the reference isodose. Ideal $\mathrm{HI}$ is $\mathrm{HI}=1$ which is described as follows $\mathrm{HI}=\mathrm{D} 95 \% / \mathrm{D} 5 \%$.

\section{Results}

\section{OAR Doses}

Individual dose estimates for lung, heart, spinal cord, and esophagus given in Table 1 for three different planning techniques. Lung V20 doses between rainbow
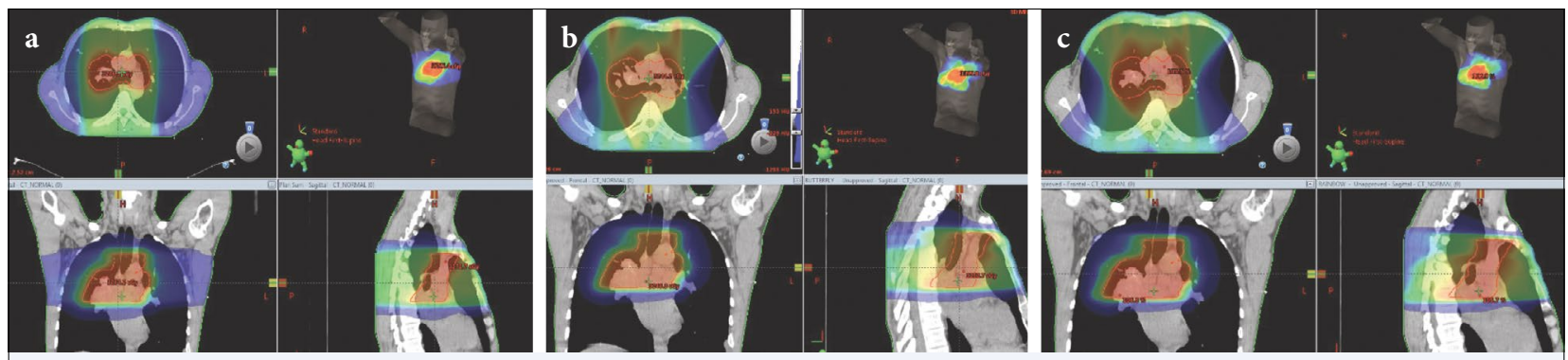

Fig. 1. (a) Sunglass technique, (b) butterfly technique, (c) rainbow technique. 
Table 1 Critical organ doses

\begin{tabular}{lccccc} 
RT technique & $\begin{array}{c}\text { Lung V20 } \\
\text { (\%) }\end{array}$ & $\begin{array}{c}\text { Lung V5 } \\
\text { (\%) }\end{array}$ & $\begin{array}{c}\text { Heart mean } \\
\text { (cGy) }\end{array}$ & $\begin{array}{c}\text { Spinal cord max } \\
\text { (cGy) }\end{array}$ & $\begin{array}{c}\text { Esophagus mean } \\
\text { (cGy) }\end{array}$ \\
\hline Rainbow & 16.21 & 41.62 & 484.48 & 2613 & 1409 \\
Butterfly & 16.07 & 43.44 & 509.26 & 2798 & 1396 \\
Sandglass & 12.72 & 50.74 & 454.62 & 2210 & 1309 \\
& $\mathrm{p}=0.001$ & $\mathrm{p}=0.035$ & $\mathrm{p}=0.01$ & $\mathrm{p}=0.001$ & $\mathrm{p}=0.02$ \\
\hline
\end{tabular}

RT: Radiotherapy; cGy: Centigrey

(range, 5.8-34.7) and butterfly (range, 5.7-35) techniques were similar whereas with sandglass (range, 3.623.9) technique, significantly reduced lung V20 doses $(\mathrm{p}=0.001)$ were observed. On the other hand, rainbow technique has advantage on lung V5 doses with respect to other two techniques ( $\mathrm{p}=0.035$ ) (range, 20.7-63). The mean doses to heart and esophagus are the lowest with sandglass technique with an average $454.62 \mathrm{cGy}$ $(\mathrm{p}=0.01)$ (range, 17.5-1202.8) and $1309 \mathrm{cGy}(\mathrm{p}=0.02)$ (range, 496.9-2102.5), respectively, also the lowest mean hotspot dose on spinal cord achieved with sandglass technique 2210 cGy ( $\mathrm{p}=0.001)$ (range, 1309-3347,6).

\section{PTV Coverage}

The mean PTV volume was $749.78 \mathrm{~cm}^{3}$ and coverage was optimally equal for all techniques. Sandglass technique is superior in terms of CI which is closer to 1 (0.88) (range, 0.79-0.94). Rainbow technique suggested difference in favor of HI (0.91) (range, 0.90-0.93). Due to technical difference of VMAT to IMRT, sandglass technique has advantage in terms of MU. Table 2 gives $\mathrm{CI}, \mathrm{HI}$, and $\mathrm{MU}$ values.

\section{Discussion}

Lymphoma RT has many difficulties such as safety and reducing late/early side effects. This study represents our planning attitude on daily clinical practice. Comparing modern RT techniques have substantial importance, this could be helpful to clinics to choose optimal technique.

Fiandra et al.[14] assessed dosimetric differences between 3D-CRT, VMAT (single and multiple arcs), helical TomoTherapy and TomoDirect. Their study showed that modulated beams have advantages on PTV coverage and OAR doses compared to 3D-CRT. Helical TomoTherapy submit most appropriate technique to balance between PTV conformity and lowintermediate doses.

Goodman et al.[15] showed that IMRT provides reduced pulmonary toxicity and improved PTV coverage
Table $2 \mathrm{Cl}, \mathrm{HI}$, and $\mathrm{MU}$ values

\begin{tabular}{lccc} 
RT technique & CI & HI & MU \\
\hline Rainbow & 0.81 & 0.91 & 728.08 \\
Butterfly & 0.76 & 0.90 & 793.73 \\
Sandglass & 0.88 & 0.88 & 483.80 \\
\hline
\end{tabular}

$\mathrm{Cl}$ : Conformity index; $\mathrm{HI}$ : Homogeneity index; MU: Monitor unit; RT: Radiotherapy

with respect to AP/PA and 3D-CRT techniques. IMRT causes low-dose bath which is a one of the serious concerns for carcinogenesis Voong et al.[16] studied comparison between five and seven field IMRT between AP/PA conformal photon plans. They concluded that IMRT provides adequate dose distributions to targets and nearby critical organs besides keep the low-dose area at decent levels such as $5 \mathrm{~Gy}$.

Filippi et al.[17] compared VMAT and 3D-CRT in terms of the secondary cancer risk for lung, breast, thyroid, and cardiac toxicity. It is shown that VMAT increased risk of lung cancer on the other side reduced risk of breast cancer. For other sides, there was no significant difference.

\section{Conclusion}

It is seen that sandglass technique has remarkable advantageous for lung V20, heart, esophagus, spinal cord, $\mathrm{CI}$, and MU. Treatment plans which have lower critical organ doses gain importance for long-term expectation patients. These techniques should be studied and evaluated for each patient. Sandglass plan was preferable for mediastinal lymphoma.

Peer-review: Externally peer-reviewed.

Conflict of Interest: All authors declared no conflict of interest.

Ethics Committee Approval: The study is a dosimetric data study, there is no Ethics Committee Approval. 
Financial Support: This study has received no financial support.

Authorship contributions: Concept - S.Y., Z.G.; Design - F.A.; Supervision - F.A.; Funding - S.Y.; Materials - S.Y.; Data collection and/or processing - S.Y.; Data analysis and/ or interpretation - S.Y., Z.G.; Literature search - S.Y., Z.G.; Writing - S.Y.; Critical review - F.A.

\section{References}

1. Pern V, Zefkili S, Peurin D, Fourquet A, Kirova Y. Can we reduce the toxicity of the mediastinal irradiation using new highly conformal techniques? J Leuk 2014;2:2-9.

2. Hasenclever D, Diehl V. A prognostic score for advanced Hodgkin's disease. International prognostic factors project on advanced Hodgkin's disease. N Engl J Med 1998;339(21):1506-14.

3. Specht L, Gray RG, Clarke MJ, Peto R. Influence of more extensive radiotherapy and adjuvant chemotherapy on long-term outcome of early-stage Hodgkin's disease: A meta-analysis of 23 randomized trials involving 3888 patients. international Hodgkin's disease collaborative group. J Clin Oncol 1998;16(3):830-43.

4. Specht $\mathrm{L}$. Does radiation have a role in advanced stage Hodgkin's or Non-Hodgkin lymphoma. Curr Treat Options Oncol 2016;17(1):4.

5. Peters MV, Middlemiss KC. A studyof Hodgkin's disease treated by irradiation. Am J Roentgenol Radium Ther Nucl Med 1958;79(1):114-21.

6. Donaldson SS, Kaplan HS. Complications of treatment of Hodgkin's disease in children. Cancer Treat Rep 1982;66(4):977-89.

7. Mauch PM, Weinstein H, Botnick L, Belli J, Cassady J. An evaluation of long-term survival and treatment complications in children with Hodgkin's disease. Cancer 1983;51(5):925-32.

8. Willman K, Cox R, Donaldson SS. Radiation induced height impairment in pediatric Hodgkin's disease. Int J Radiat Oncol Biol Phys 1994;28(1):85-92.

9. Moskowitz CS, Chou JF, Wolden SL, Bernstein JL, Malhotra J, Friedman DN, et al. Breast cancer after chest radiation therapy for childhood cancer. J Clin Oncol 2014;32(21):2217-23.

10. Ng AK, Bernardo MP, Weller E, Backstrand KH, Silver B, Marcus KC, et al. Long-term survival and competing causes of death in patients with early-stage Hodgkin's disease treated at age 50 or younger. J Clin Oncol 2002;20(8):2101-8.

11. Goodman KA, Toner S, Hunt M, Wu EJ, Yahalom J. Intensity-modulated radiotherapy for lymphoma involving the mediastinum. Int J Radiat Oncol Biol Phys 2005;62(1):198-206.

12. Xu LM, Kang ML, Jiang B, Liu QF, Li YX. A study of the dosimetric characteristics between different fixed-field IMRT and VMAT in early-stage primary mediastinal B-cell lymphoma. Med Dosim 2018;43(1):91-9.

13. Weber DC, Peguret N, Dipasquale G, Cozzi L. Involved-node and Involved-field volumetric modulated arc vs.fixed beam Intensity-modulated radiotherapy for female patients with early-stage supra-diaphragmatic Hodgkin lymphoma: A comparative planning study. Int J Radiat Oncol Biol Phys 2009;75(5):157886.

14. Fiandra C, Filippi AR, Catuzzo P, Botticella A, Ciammella P, Franco P, et al. Different IMRT solutions vs. $3 \mathrm{D}$-conformal radiotherapy in early stage Hodgkin's Lymphoma: Dosimetric comparison and clinical considerations. Radiat Oncol 2012;2(7):186.

15. Goodman K, Toner S, Hunt M, Wu EJ, Yahalom J. Intensity-modulated radiotherapy for lymphoma involving the mediastinum. Int J Radiat Oncol Biol Phys 2005;62(1):198-206.

16. Voong KR, McSpadden K, Pinnix CC, Shihadeh F, Reed V, Salehpour MR, et al. Dosimetric advantages of a "butterfly" technique for intensity-modulated radiation therapy for young female patients with mediastinal Hodgkin's lymphoma. Radiat Oncol 2014;9:94.

17. Filippi AR, Ragona R, Piva C, Scafa D, Fiandra C, Fusella $\mathrm{M}$, et al. Optimized volumetric modulated arc therapy versus 3D-CRT for early stage mediastinal Hodgkin lymphoma without axillary involvement: A comparison of second cancers and heart disease risk. Int J Radiat Oncol Biol Phys 2015;92(1):161-8. 